Journal of Patient-Centered

Volume 8

Issue 4 - Cancer Screening

Article 9

10-18-2021

\title{
Impact of COVID-19 on Screening Rates for Colorectal, Breast, and Cervical Cancer: Practice Feedback From a Quality Improvement Project in Primary Care
}

\author{
Laura A. Schad \\ Laura A. Brady \\ Laurene M. Tumiel-Berhalter \\ Alexandrea Bentham \\ Karen Vitale \\ Amanda Norton \\ Gary Noronha \\ Carlos Swanger \\ Christopher P. Morley
}

Follow this and additional works at: https://aah.org/jpcrr

Part of the Community Health and Preventive Medicine Commons, Health Services Research

Commons, Infectious Disease Commons, Oncology Commons, and the Quality Improvement Commons

\section{Recommended Citation}

Schad LA, Brady LA, Tumiel-Berhalter LM, Bentham A, Vitale K, Norton A, Noronha G, Swanger C, Morley CP. Impact of COVID-19 on screening rates for colorectal, breast, and cervical cancer: practice feedback

from a quality improvement project in primary care. J Patient Cent Res Rev. 2021;8:347-53. doi: 10.17294/ 2330-0698.1856

Published quarterly by Midwest-based health system Advocate Aurora Health and indexed in PubMed Central, the Journal of Patient-Centered Research and Reviews (JPCRR) is an open access, peer-reviewed medical journal focused on disseminating scholarly works devoted to improving patient-centered care practices, health outcomes, and the patient experience. 


\title{
Impact of COVID-19 on Screening Rates for Colorectal, Breast, and Cervical Cancer: Practice Feedback From a Quality Improvement Project in Primary Care
}

\author{
Laura A. Schad, MPH, ${ }^{1}$ Laura A. Brady, $\mathrm{PhD},{ }^{2}$ Laurene M. Tumiel-Berhalter, $\mathrm{PhD},{ }^{2,3}$ Alexandrea \\ Bentham, BS, ${ }^{2}$ Karen Vitale, MSEd, ${ }^{4}$ Amanda Norton, MSW, ${ }^{5}$ Gary Noronha, MD, ${ }^{6}$ Carlos Swanger, \\ MD, ${ }^{6,7}$ Christopher P. Morley, PhD, MA ${ }^{1}$ \\ ${ }^{1}$ Department of Public Health and Preventive Medicine, State University of New York (SUNY) Upstate Medical \\ University, Syracuse, NY; ${ }^{2}$ Department of Family Medicine, SUNY University at Buffalo, Buffalo, NY; ${ }^{3}$ University at \\ Buffalo Clinical and Translational Science Institute, Buffalo, NY; ${ }^{4}$ University of Rochester, Clinical and Translational \\ Science Institute, Rochester, NY; ${ }^{5}$ A. Mandatory, Inc. (consulting for SUNY Upstate Medical University), Groton, NY; \\ ${ }^{6}$ Center for Primary Care, Department of Medicine, University of Rochester School of Medicine and Dentistry, \\ Rochester, NY; ${ }^{7}$ Health Reach for the Homeless, Rochester Regional Health, Rochester, NY
}
Purpose Three New York State practice-based research networks provided quality improvement strategies to improve screening rates for breast, cervical, and colorectal (BCC) cancers in safety-net primary care, over 7 years. In the final year (Y7), the United States experienced the COVID-19 pandemic. The impact of the COVID-19 pandemic on BCC cancer screening rates was assessed qualitatively.

Methods A total of 12 primary care practices participated in $\mathrm{Y} 7$ of the quality improvement project. BCC cancer screening rates at year beginning and end were assessed. Practice staff were asked about how COVID-19 impacted screening. Average pre/postintervention screening rates and qualitative thematic analysis regarding how COVID-19 impacted cancer screening were ascertained.

Results In Y7, there was an increase in breast cancer and a decrease in colorectal and cervical cancer screening rates compared to the previous project year. Many practices were able to continue pre-COVID-19 cancer screening processes. Overall, practices reported loss of staff, changes in data entry, and a shift from preventive screening to care of sick patients. Telehealth was vital for practices to continue serving patients but had a less positive impact on patients with financial/technological disadvantages. BCC cancer screenings were impacted at various levels.

Conclusions The COVID-19 pandemic negatively impacted primary care practice cancer screening; however, some practices were able to mitigate effects by shifting focus to processes supporting screening outside of in-person office visits. (J Patient Cent Res Rev. 2021;8:347-353.)

Keywords $\quad$ cancer screening; primary care; COVID-19; breast cancer; colorectal cancer; cervical cancer; telehealth

$I^{\prime}$ $\mathrm{n}$ the United States, screening rates for colorectal, breast, and cervical cancer often fall below national targets despite the current evidence of preventive screening effectiveness. ${ }^{1}$ Compounding the problem, screening rates in disadvantaged populations are generally worse than for more well-off segments of society. This is true in New York State, prompting the New York State

Corresponding author: Christopher P. Morley,

Department of Public Health and Preventive Medicine, Upstate Medical University, 750 E. Adams St., Weiskotten Hall 2262, Syracuse, NY 13210 (MorleyCP@upstate.edu)
Department of Health to target primary care practices serving disadvantaged populations - known as safetynet practices - to engage them in improving screening rates within their patient panels.

Responding to this call, three practice-based research networks administered across central and western New York State partnered to provide quality improvement (QI) strategies on colorectal, breast, and cervical cancer screening through practice facilitation ${ }^{2-4}$ and academic detailing $^{5-7}$ to increase screening rates in safety-net primary care practices over 7 years (2014-2020), ending in June 2020. Characteristics of the populations served and practice types are reported elsewhere, but briefly, our safety-net clinics represented a mix of practices that 
included Federally Qualified Health Centers and academic practices that saw patients who were underserved, either through uninsurance, poor insurance, or lack of access due to other reasons such as geographic or community features. Aggregate increases in screening rates were observed across participating practices for colorectal and breast cancer, with more uneven results for cervical cancer. Details of the overall project and outcomes are available elsewhere. ${ }^{1,8-15}$

In the seventh and final year of this project (July 2019June 2020), the United States was beset by the COVID-19 global pandemic. The delivery of health care was dramatically changed during this time. Preventive care services were curtailed, patients feared going to a health care facility, and social distancing required practices to completely change their practice workflows. Regions of New York State covered by our QI project spent the final months of participation (March-June) socially distancing and in mandated business closures, with travel and mobility restrictions in place throughout the state. ${ }^{16,17}$ These measures had dramatic impacts on primary care practice operations in the last 4 months of project year 7 (Y7), a time frame in previous years during which practices were well into their interventions and routines and winding down project-related activities.

As part of our regular close-out procedures at the end of each project year, practice personnel participated in key informant interviews to discuss operations from the prior year. Given the potential impact of COVID-19 responses on the provision of preventive services, we added discussion of COVID-19 to our end-of-year interviews in 2020. The purpose of this paper is to describe key informant impressions of the impact of the COVID-19 pandemic on preventive screenings within our participating safety-net practices, both to inform and contextualize the impact on screening rates as well as to elucidate any lessons that may be learned as the pandemic continues.

\section{METHODS}

Twelve safety-net primary care practices participated in the final year of the project, which was determined to be non-research quality improvement by the institutional review board of State University of New York Upstate Medical University. To assess the overall impact of the project, colorectal, breast, and cervical screening rates were collected from the 12 practices at two times during each project year - once at the start of each intervention year (pre) and once at the end of each intervention year (post). The time frame for pre and post data varied among practices and was based on when each practice entered the project. Data were collected as part of the annual program evaluation and include numerators representing the total number of eligible patients screened within a given time frame and denominators representing the total number of patients eligible for screening in that same time frame. The number of patients screened was collected by method of screening for each cancer; however, many practices left these fields blank. Screening rates for each cancer were aggregated to descriptively evaluate trends in screening rates from August 2019 to June 2020.

In addition to quantitation of screening rate changes, key informants from all 12 practices participated in end-ofyear open-ended interviews with a practice facilitator from the project, including discussion of the perceived impacts of the COVID-19 pandemic on colorectal, breast, and cervical cancer screening. The discussions were held naturalistically, with guide questions indicating the direction of discussion but not dictating the dialogue. Qualitative comments pertaining to COVID-19 were collated by the practice facilitators conducting the interviews and entered into a shared online form (Google Docs). Responses were organized by each cancer screening type or as overarching comments pertaining to the impact of the pandemic on general cancer screening priorities and issues across all types.

Once responses from all 12 practices were collated, they were assessed via brief content analysis, which involved grouping statements based on similar and reoccurring keywords and themes. This process was led by one team member who had not participated in the interviews and was cross-validated by a second team member who also had not participated in the interviews. Both of these individuals have formal training in qualitative data analysis. The identified themes were then discussed with the broader team of authors, including interviewer/practice facilitators, for a third interpretive and analytic step. All responses were coded without identifying information.

Results include the themes identified in the qualitative responses and quantitative description of rate changes for colorectal, breast, and cervical cancer screening. Other results and outcomes from the project are reported elsewhere in this issue of Journal of Patient-Centered Research and Reviews. ${ }^{14,15}$

\section{RESULTS}

An overall increase in mean screening rates was seen from pre-Y1 to post-Y6 of this project for breast and colorectal cancers, while cervical cancer screening rates showed an overall decrease. ${ }^{15}$ In $\mathrm{Y} 7$, colorectal screening saw the most change ( 2 percentage point decrease) while cervical screening remained almost unchanged $(0.10$ percentage point decrease). Breast cancer screening increased by about 1 percentage point from the pre-Y7 to post-Y7 period. 
All practices responded to the request for information regarding screenings and COVID-19. Two of the practices reported no changes in screening across all cancer types during the pandemic, 1 practice reported slight changes in screening across all cancer types, and 2 practices reported major changes in screening across all cancer types during this time. The remaining practices all reported varying degrees of change for colorectal, breast, and cervical cancer.

Cervical cancer was reported by the majority of practices as the least likely screening to experience a change of any magnitude due to the pandemic, followed closely by colorectal cancer. Breast cancer was the most likely screening to experience both slight and major changes due to COVID-19. A total of 13 themes were codified, with 5 overarching themes and 2 each pertinent to colorectal, breast, and cervical cancer.

\section{Overarching Themes}

Continued Pre-COVID-19 Processes. Several practices indicated they attempted to continue pre-COVID-19 screening and referral practices to the greatest extent possible while experiencing reduced patient volumes.

Changes in Data Entry During This Time. Some practices experienced delays in data entry due to staffing changes; however, others reported that the slowdown in in-office activity offered the opportunity to "clean up" existing data.

Telehealth Heavily Relied on During Pandemic, Its Use Likely to Continue. Many practices switched to telehealth for the delivery of all services. Those with established experience and infrastructure to deliver telehealth had more success than those who had to implement these processes as a reactive step to a COVID-19 shutdown.

Focus Shifted From Preventive Screening to Caring for Sick Patients. This was observed across all cancer types; preventive screening was de-emphasized during COVID-19 shutdowns.

Many Practices Experienced Decreased Staffing During This Time. A major impediment was the decrease in staffing levels during COVID-19 shutdowns.

\section{Colorectal Cancer Screening Themes}

Shifted Focus From Preventive Screening. Several practices indicated that focus had to be shifted away from all preventive care, such as screening, as demands for acute care and COVID-19 testing took precedence.

Change in Number of Mailed FIT Kits and Commercial FIT-DNA Tests. The availability of fecal testing (fecal immunochemical test [FIT] and commercial FIT-DNA) allowed practices to shift some of the burden of screening from in-office, appointment-driven approaches (eg, colonoscopy) to home-based procedures.

\section{Breast Cancer Screening Themes}

Screenings Paused During Summer of 2020. Several practices paused breast cancer screening, especially since there was no in-home option (such as those available for colorectal screening).

Practices Relied on Then-Unavailable Mobile Mammography Units. Some practices indicated that mobile mammography units funded by New York State were the primary means of breast cancer screening referral; these units stopped operating at the height of COVID-19 shutdowns, with some units being operationalized as mobile COVID-19 testing facilities.

\section{Cervical Cancer Screening Themes}

Our safety-net primary care practices (family medicine and general internal medicine) primarily rely on gynecology referrals and separate providers to manage cervical cancer screening. During the COVID-19 shutdowns, many practices opted not to focus on cervical screening. This change in focus resulted, for some practices, in a stop in cervical screening and referrals for screening altogether.

Quotes supporting and illustrating identified themes are included in Tables 1-4.

\section{DISCUSSION}

Colorectal cancer screening seemed to be relatively unchanged by the pandemic; many practices were already mailing test kits to patients who were due for a screening, and this continued whether or not patients could be seen in the office. Practices also had time to follow up with patients who had had a positive FIT kit before the pandemic hit, with one practice utilizing the services of patient navigators to keep in contact with these individuals, ensuring they could be scheduled for follow-up as soon as the practice was ready. While most practices increased the number of FIT kits and commercial FIT-DNA tests mailed, one practice decreased them, citing concerns over potential exposure of the samples to COVID-19 through the laboratory they used. While the delay in the mailing of test kits or the inability to schedule in-person appointments may have impacted diagnostic ability, none of the practices reported this as a concern.

For breast cancer, several practice sites involved with the project utilized the services of mobile mammography vans or buses within the communities they serve. Historically, these mobile units increase the number of screenings that can be done by a practice and address issues of 
Table 1. Overarching Themes ${ }^{a}$

\begin{tabular}{|c|c|}
\hline Theme & Quotes from practices \\
\hline $\begin{array}{l}\text { Continued pre-COVID-19 } \\
\text { processes }\end{array}$ & $\begin{array}{l}\text { "The QI team did outreach and follow-up after mailing FIT kits, and GI continued to } \\
\text { schedule colonoscopies." } \\
\text { "We still handed out FIT kits to patients who came in." } \\
\text { "We're slightly backlogged from before the pandemic, but the mammography bus is still } \\
\text { doing two times a month." } \\
\text { "We see the greatest success with getting patients to complete this screening [breast] } \\
\text { because it is the least invasive and requires very limited interaction with a medical site." } \\
\text { "We continued to refer out for Pap smears." }\end{array}$ \\
\hline $\begin{array}{l}\text { Changes in data entry during } \\
\text { this time }\end{array}$ & $\begin{array}{l}\text { "There was delay in entering screening data, which led to inaccurate rates." } \\
\text { "Our practice also had some time available to go in and 'clean up' patient records and data, } \\
\text { which was valuable." }\end{array}$ \\
\hline $\begin{array}{l}\text { Telehealth was heavily relied } \\
\text { on during this time, and } \\
\text { practices will likely continue } \\
\text { to use this technology }\end{array}$ & $\begin{array}{l}\text { "The practice plans to continue using telemed after the pandemic so long as it continues to } \\
\text { be covered/reimbursed." } \\
\text { "The practice will continue telemed if they are able to and it is an option for patients, but } \\
\text { many are underserved or don't have the means to use." } \\
\text { "The ability to use telehealth was very helpful for our practice, allowing for better } \\
\text { conversations with patients." }\end{array}$ \\
\hline $\begin{array}{l}\text { Focus shifted from preventive } \\
\text { screening to caring for sick } \\
\text { patients }\end{array}$ & $\begin{array}{l}\text { "Lots of testing for COVID-19. The immediate focus was to get people in if they were sick } \\
\text { or needed testing, before focusing on additional screenings." } \\
\text { "The focus at the practice has been on sick or necessary visits, as little to no cancer } \\
\text { screening was being done during more hectic times in pandemic." }\end{array}$ \\
\hline $\begin{array}{l}\text { Many practices experienced } \\
\text { decreased staffing during } \\
\text { this time }\end{array}$ & $\begin{array}{l}\text { "Over the summer, our practice had about half the nursing staff still in office and others } \\
\text { working from home if possible." } \\
\text { "At this practice, there were far fewer people to support the work due to the loss of staff for } \\
\text { several reasons. Some were exposed to or contracted COVID-19 and some had their time } \\
\text { reallocated to hospitals to support the response." } \\
\text { "Three care coordinators were furloughed during the pandemic." }\end{array}$ \\
\hline
\end{tabular}

a Themes were developed from practice responses to the question, "Each previous question was asked about screening for specific cancer types. Is there anything you would add as an overall comment, as additional information, or as a summary?"

FIT, fecal immunochemical test; GI, gastroenterology; QI, quality improvement; telemed, telemedicine.

accessibility for patients who are due for screening. ${ }^{18,19}$ During the pandemic, many of these mobile screening units were repurposed for COVID-19 testing, which severely impacted the ability of practices who relied on these units to conduct breast cancer screening. Once rates of infection slowed in New York State and practices adjusted to a "new normal," they were able to slowly ramp up breast cancer screenings. Some practices regained access to their mobile mammography units, but others did not.

According to anecdotal reports from our own participating practices, cervical cancer screening has historically been difficult for primary care practices to target and track because many patients seek this service at outside obstetrics/gynecology (OB/GYN) facilities. Sharing information across practice sites requires dedicated effort, and practices do not always have the bandwidth to track these screening records. Cervical cancer screening continued to be a problem for many sites during the onset of COVID-19 restrictions, with many OB/GYN clinics closed for preventive care and fewer staff available to monitor patient data between sites.

Practices who historically serve high-risk populations, including homeless, refugee, and elderly patients, encouraged these individuals to stay home if they were healthy. Some practices closed entirely for periods of time, and many practices saw reduced staffing from sickness or reassignment to help hospitals with their overwhelming need. A few practices saw the decrease of patient visits as an opportunity to improve their preventive screenings, either by cleaning up patient records and data or by filming screening tutorial videos that can be used for all patients, including after the pandemic.

Telehealth was extremely useful for practices during this time. Many stated that they will continue to use telehealth as long as it remains reimbursable. However, telehealth 
Table 2. "Did your approach to screening patients for colorectal cancer change at all as a result of the COVID-19 pandemic? If it did not - please say so. If it did change - how?"

\begin{tabular}{l|l}
\hline Theme & Quotes from practices \\
\hline $\begin{array}{l}\text { Shifted focus from preventive } \\
\text { screenings }\end{array}$ & $\begin{array}{l}\text { "We continued to offer FIT kits but focused mainly on sick or immediate appointments." } \\
\text { "Our focus was on outreach instead of in-office screening." }\end{array}$ \\
\hline $\begin{array}{l}\text { Change in the number of FIT } \\
\text { kits and commercial FIT-DNA } \\
\text { tests that were mailed }\end{array}$ & $\begin{array}{l}\text { "We focused solely on mailing FIT kits because patients could not come in for colonoscopies } \\
\text { "We printed lists of everyone who was due and created ... [commercial FIT-DNA] orders } \\
\text { for patients ... mailed letters to those who already had kits but hadn't completed them, and } \\
\text { those with old FIT kits received a new ... [commercial FIT-DNA] order." } \\
\text { "We pulled back on mailing FIT kits because results are run by an internal lab and there } \\
\text { were concerns about exposure [to COVID-19] with receiving returned sample." }\end{array}$ \\
\hline
\end{tabular}

FIT, fecal immunochemical test.

Table 3. "Did your approach to screening patients for breast cancer change at all as a result of the COVID-19 pandemic? If it did not - please say so. If it did change - how?"

\begin{tabular}{l|l}
\hline Theme & Quotes from practices \\
\hline $\begin{array}{l}\text { Screenings were paused } \\
\text { during the summer of } 2020\end{array}$ & $\begin{array}{l}\text { "As of September 2020, our practice has slowly begun rescheduling and making } \\
\text { appointments." } \\
\text { "Patients were unable to come in for mammograms, so the focus was on mailing } \\
\text { information to those who were due." }\end{array}$ \\
\hline $\begin{array}{l}\text { Practices relied on mobile } \\
\text { mammography units that }\end{array}$ & $\begin{array}{l}\text { "The mammography bus was temporarily halted but began again in June 2020. Fewer } \\
\text { people are getting screened, but still continuing." } \\
\text { "Mobile mammography is no longer available, as it was turned into a mobile COVID-19 } \\
\text { testing site." }\end{array}$ \\
\hline
\end{tabular}

Table 4. "Did your approach to screening patients for cervical cancer change at all as a result of the COVID-19 pandemic? If it did not - please say so. If it did change - how?"

\begin{tabular}{l|l}
\hline Theme & Quotes from practices \\
\hline $\begin{array}{l}\text { Cervical cancer screening was } \\
\text { no longer a central focus }\end{array}$ & $\begin{array}{l}\text { "Cervical had been a focus but also a struggle to improve. At this point, it is not a key focus } \\
\text { "We focus on outreach instead of in-office screening." }\end{array}$ \\
\hline $\begin{array}{l}\text { No screening or referrals } \\
\text { occurred }\end{array}$ & $\begin{array}{l}\text { "Our practice started offering Pap smears in-office this year but had to delay this during } \\
\text { initial COVID-19 impacts." } \\
\text { "Little to no screening occurred during this time, as it wasn't a priority." }\end{array}$ \\
\hline
\end{tabular}

presented issues when patients did not have the means to access the technology necessary for appointments. Practices that had experience using telehealth tended to be more comfortable, and more successful, with its use during COVID-19 operational restrictions.

One practice noted that the greatest barriers to screenings are now patient financial concerns. In a time when income is potentially much more limited due to unemployment, patients may be unable to pay for screening or for potential follow-up if a screening is positive.

\section{Limitations}

One limitation of this study is the inability to compare the months of the pandemic in Y7 (March-June) with those same months from previous project years. Our data were collected at two time points each year based on prescribed dates. Without screening rate data for each month, we 
are unable to directly compare screening rates solely for March-June 2020. Our analysis focused on qualitative reports from practices that reported the changes they saw on the ground rather than quantitative screening data.

\section{CONCLUSIONS}

Despite dramatic changes in operations when COVID-19 restrictions took effect in the spring of 2020, primary care practices participating in our project were able to shift focus from traditional cancer screening support (usually involving direct patient communication during an office visit) to processes that support screening outside of in-person office visits. These include shifting colorectal cancer screening to home-based fecal testing methods, the use of telehealth to assess and communicate with patients, and the use of staff time for database and registry cleaning to identify more patients due for screening when the capacity to do so returned. Also, most practices were on improvement trajectories with their screening rates, and these trajectories flattened during the pandemic response. However, a dramatic decline in screening was not observed, rather, practices deployed creative problem-solving to maintain screening rates as COVID-19 restrictions took hold.

\section{Patient-Friendly Recap}

- The COVID-19 pandemic disrupted cancer screening workflows of safety-net primary care practices, many of which experienced loss of dedicated staff or relied on OB/GYN offices that halted preventive screenings.

- Telehealth, though available in primary care prior to COVID-19, became further integrated into practices and a vital aspect to the continuation of screenings. However, it was less impactful for patients with financial or technological disadvantages.

- Practices adapted to maintain prepandemic screening rates by increasing the accuracy of electronic medical records, reaching out to patients regarding their screening, referring patients for off-site mammography, and mailing lab tests for colorectal cancer.

\section{Acknowledgments}

We owe our deepest gratitude to the primary care practices and their teams that participated in the final year of the project while adapting their practices to respond to the COVID-19 pandemic and are indebted to the physicians, advanced practice providers, nurses, and practice staff at each site. Our project manager and practice facilitators continued to engage with practices and support their cancer screening efforts during the pandemic. We also are extremely grateful to our collaborators at the New York State Department of Health who recognized the value of these efforts and were committed to finding practice-based solutions to increase preventive cancer screening for underserved communities.

\section{Author Contributions}

Study design: Schad, Morley. Data acquisition or analysis: all authors. Manuscript drafting: Schad, Brady, Morley. Critical revision: Brady, Tumiel-Berhalter, Bentham, Vitale, Norton, Noronha, Swanger.

\section{Conflicts of Interest}

None.

\section{Funding Sources}

This publication was supported by cooperative agreements NU58DP6102, NU58DP006309, U58DP002029, and U58DP003879, funded by the Centers for Disease Control and Prevention (CDC). Its contents are solely the responsibility of the authors and do not necessarily represent the official views of the CDC or the Department of Health and Human Services, Health Research, Inc., or the New York State Department of Health.

\section{References}

1. Mader EM, Fox CH, Epling JW, et al. A practice facilitation and academic detailing intervention can improve cancer screening rates in primary care safety net clinics. J Am Board Fam Med. 2016;29:533-42. CrossRef

2. Agency for Healthcare Research and Quality. Module 1. Practice facilitation as a resource for practice improvement. Page last reviewed May 2013; accessed August 12, 2020. https://www.ahrq.gov/ncepcr/tools/pf-handbook/mod1.html

3. Weiner BJ, Rohweder CL, Scott JE, et al. Using practice facilitation to increase rates of colorectal cancer screening in community health centers, North Carolina, 2012-2013: feasibility, facilitators, and barriers. Prev Chronic Dis. 2017;14:E66. $\underline{\text { CrossRef }}$

4. Baskerville NB, Liddy C, Hogg W. Systematic review and meta-analysis of practice facilitation within primary care settings. Ann Fam Med. 2012;10:63-74. CrossRef

5. O'Brien MA, Rogers S, Jamtvedt G, et al. Educational outreach visits: effects on professional practice and health care outcomes. Cochrane Database Syst Rev. 2007;2007(4):CD000409. CrossRef

6. Dignan M, Shelton B, Slone SA, et al. Effectiveness of a primary care practice intervention for increasing colorectal cancer screening in Appalachian Kentucky. Prev Med. 2014;58:70-4. CrossRef

7. Young JM, Ward JE. Strategies to improve cancer screening in general practice: Are guidelines the answer? Fam Pract. 1999;16:66-70. CrossRef

8. Morley CP, Mader EM, Schad L; STFM Resource Library. Increasing colorectal cancer screening through academic detailing and practice facilitation - project summary report August 2014. Posted October 5, 2020; accessed August 17, 2021. https://resourcelibrary.stfm.org/viewdocument/ increasing-colorectal-cancer-screen

9. Mader EM, Bennett BE, Morley CP, Schad L; STFM Resource Library. Increasing breast, cervical and colorectal cancer screening through academic detailing and practice facilitation project summary report July 2015. Posted October 5, 2020; accessed August 17, 2021. https:// resourcelibrary.stfm.org/viewdocument/increasing-breastcervical-and-col?CommunityKey $=2751$ b51d-483f-45e2$\underline{81 \mathrm{de}-4 \text { faced0a290a\&tab=librarydocuments }}$ 
10. Mader EM, Pratte MA, Morley CP, Schad L; STFM Resource Library. Increasing breast, cervical and colorectal cancer screening through academic detailing and practice facilitation - project summary report August 2016. Posted October 5, 2020; accessed August 17, 2021. https://resourcelibrary. stfm.org/viewdocument/increasing-breast-cervical-andcol-1 ? CommunityKey=2751b51d-483f-45e2-81de4faced0a290a\&tab=librarydocuments

11. Pratte MA, Morley CP, Schad L; STFM Resource Library. Increasing breast, cervical and colorectal cancer screening through academic detailing and practice facilitation project summary report August 2017. Posted October 5, 2020; accessed August 17, 2021. https://resourcelibrary. stfm.org/viewdocument/increasing-breast-cervical-andcol-2? CommunityKey=2751b51d-483f-45e $2-81 \mathrm{de}-$ 4 faced0a290a\&tab=librarydocuments

12. Brady L, Hamouda A, Tumiel-Berhalter L, Schad L, Morley CP; STFM Resource Library. Increasing breast, cervical and colorectal cancer screening through academic detailing and practice facilitation - project summary report August 2018. Posted October 5, 2020; accessed August 17, 2021. https:// resourcelibrary.stfm.org/viewdocument/increasing-breastcervical-and-col-3?CommunityKey $=2751$ b51d-483f-45e2$\underline{\text { 81de-4faced0a290a\&tab=librarydocuments }}$

13. Brady L, Bentham A, Tumiel-Berhalter L, Schad L, Morley CP; STFM Resource Library. Increasing breast, cervical and colorectal cancer screening through academic detailing and practice facilitation - project summary report August 2019. Posted October 5, 2020; accessed August 17, 2021. https:// resourcelibrary.stfm.org/viewdocument/increasing-breastcervical-and-col-4
14. Brady LA, Tumiel-Berhalter LM, Schad LA, et al. Increasing breast, cervical, and colorectal cancer screenings: a qualitative assessment of barriers and promoters in safety-net practices. J Patient Cent Res Rev. 2021;8:323-30.

15. Morley CP, Schad LA, Tumiel-Berhalter LM, et al. Improving cancer screening rates in primary care via practice facilitation and academic detailing: a multi-PBRN quality improvement project. J Patient Cent Res Rev. 2021;8:315-22.

16. Morley CP. Assessing the impact of social distancing during COVID-19. JPHMP Direct. Epub 2020 Jul 23. Accessed August 17, 2021. https://jphmpdirect.com/2020/07/23/ assessing-the-impact-of-social-distancing-during-covid-19/

17. Morley CP, Anderson KB, Shaw J, Stewart T, Thomas SJ, Wang D. Social distancing metrics and estimates of SARS-CoV-2 transmission rates: associations between mobile telephone data tracking and R. J Public Heal Manag Pract. 2020;26:606-12. CrossRef

18. Vang S, Margolies LR, Jandorf L. Mobile mammography participation among medically underserved women: a systematic review. Prev Chronic Dis. 2018;15:E140. CrossRef

19. Peek ME, Han J. Mobile mammography: assessment of selfreferral in reaching medically underserved women. J Natl Med Assoc. 2007;99:398-403.

(C) 2021 Advocate Aurora Health, Inc. 